\title{
NETWORK THEORY AND SMALL GROUPS
}

NANCY KATZ

Harvard University

DAVID LAZER

Harvard University

HOLLY ARROW

University of Oregon

NOSHIR CONTRACTOR

University of Illinois at Urbana-Champaign

\begin{abstract}
This article describes the network approach to small groups. First, the core constructs that compose social network research are explained. The primary theories that provide the intellectual underpinning of the network approach are described, including theories of self-interest, theories of social exchange or dependency, theories of mutual or collective interest, cognitive theories, and theories of homophily. Highlights of the empirical work examining the internal and external networks of small groups is summarized. Finally, the primary challenges researchers face when applying the network perspective to small groups, and the primary benefits that can accrue to researchers who adopt that perspective, are enumerated.
\end{abstract}

Keywords: groups; teams; networks; theory

The last decade has seen a tremendous surge in research on social networks and research on small groups. A relatively small but growing body of work embraces both these foci. Indeed, research on the networks of small groups is fast emerging as an area of study (Lazer \& Katz, 2003b). This article provides an overview of the network approach to small groups. The intended audience is small group researchers who are curious about how network ideas and methods can enhance their understanding of small group phenomena.

SMALL GROUP RESEARCH, Vol. 35 No. 3, June 2004 307-332 DOI: $10.1177 / 1046496404264941$

(c) 2004 Sage Publications 
The article is organized into five sections. The first section is an introduction to the network perspective. Basic questions are addressed: What is a network? What are the essential dimensions along which networks meaningfully vary? How are networks measured? And, What is the definition of a small group, from the network perspective? The second section is an overview of the central principles and the theoretical underpinnings of the network perspective. The third section traces the history of empirical research on the networks of small groups. The fourth section describes the benefits that result from adopting a network perspective when studying small groups. The final section is a discussion of the primary challenges now facing researchers who apply the network perspective to small groups.

\section{INTRODUCTION TO THE NETWORK PERSPECTIVE}

What is a network? A social network consists of a set of actors ("nodes") and the relations ("ties" or "edges") between these actors (Wasserman \& Faust, 1994). The nodes may be individuals, groups, organizations, or societies. The ties may fall within a level of analysis (e.g., individual-to-individual ties) or may cross levels of analysis (e.g., individual-to-group ties).

What are the essential dimensions along which networks vary? Network researchers have examined a broad range of types of ties. These include communication ties (such as who talks to whom, or who gives information or advice to whom), formal ties (such as who reports to whom), affective ties (such as who likes whom, or who trusts whom), material or work flow ties (such as who gives money or other resources to whom), proximity ties (who is spatially or electronically close to whom), and cognitive ties (such as who knows who knows whom). Networks are typically mutiplex, that is, actors share more than one type of tie. For example, two academic colleagues might have a formal tie (one is an assistant professor and reports to the other, who is the department chairperson) 
and an affective tie (they are friends) and a proximity tie (their offices are two doors away).

Network researchers have distinguished between strong ties (such as family and friends) and weak ties (such as acquaintances) (Granovetter, 1973, 1982). This distinction can involve a multitude of facets, including affect, mutual obligations, reciprocity, and intensity. Strong ties are particularly valuable when an individual seeks socioemotional support and often entail a high level of trust. Weak ties are more valuable when individuals are seeking diverse or unique information from someone outside their regular frequent contacts. This information could include new job or market opportunities.

Ties may be nondirectional (Joe attends a meeting with Jane) or vary in direction (Joe gives advice to Jane vs. Joe gets advice from Jane). They may also vary in content (Joe talks to Jack about the weather and to Jane about sports), frequency (daily, weekly, monthly, etc.), and medium (face-to-face conversation, written memos, e-mail, instant messaging, etc.). Finally, ties may vary in sign, ranging from positive (Joe likes Jane) to negative (Joe dislikes Jane).

How are networks measured? In one common type of network study, every member of an organization is presented with a list of every other member of the organization. Respondents are asked to put a checkmark next to every person on the list with whom they have contact. Respondents might also be asked to indicate how often they have contact, or the substance of those interactions. These self-report data are translated into a sociogram using visualization software such as NetDraw (Borgatti, 2003), NetVis (Cummings, 2004), and Pajek (Batagelj \& Mrvar, 2003). A sociogram is a visual display of all of the nodes and ties in a network. A sociogram can use a variety of algorithms to organize the layout of the nodes on the network visualization. Common layouts include random assignments, placing the nodes in a circle, arranging them based on certain attributes of the nodes (putting all females or all managers close to one another), or "annealing" the network, where nodes that are tied (or more strongly tied) to one 
another are in closer proximity to each other than nodes that are not tied (or are more weakly tied) to them. The sociogram shows whether there are many or few ties between organization members, the overall pattern of those ties, and where every individual respondent is situated in the network.

Whereas the sociogram can provide a general sense of the network at a glance, researchers have developed a variety of metrics for quantifying important differences in network structure. Frequently used metrics include actor degree centrality (the extent to which actors send or receive direct ties), betweenness centrality (the extent to which actors have ties with others who are not directly connected), closeness centrality (the extent to which actors are directly or indirectly connected to the rest of the actors in the network), reciprocity (the extent to which there are mutual ties between actors), and transitivity (the extent to which actors who are connected to one another are also connected to the same other actors).

How is a group defined, from the network perspective? The construct of a group, when used in the social network literature, has had two primary meanings: (a) a structural feature of a network, or (b) an exogenously determined or imposed category. According to the first meaning, groups (cliques) are subsets of fully connected, or almost fully connected, nodes within some population. A group is an emergent phenomenon. An example would be the numerous social cliques identified in the classic anthropological study of a small city in the 1930s deep South (A. Davis, Gardner, \& Gardner, 1941). Membership in the cliques was inferred from the pattern of people's attendance at events like church suppers, card parties, and PTA meetings.

Methodologically, the study of group or subgroup formation requires a set of criteria for classifying a given set of relations as a group. Although the definition of a clique (a fully connected set of relations) is unproblematic in the case of binary choices (Wasserman \& Faust, 1994), the issue of choosing cutoff values becomes more complex for rankings (e.g., Newcomb, 1961). Choosing cutoff values is also more complex when one wishes to 
relax the balance theory-inspired requirement of complete transitivity among all within-group relations. Freeman (1992) has tackled this problem by applying the distinction between strong and weak ties to distinguish subgroups within a larger network of ties in which they are embedded.

The second definition of a group is an exogenously determined category or boundary around a set of people (e.g., a corporation, a political party, or students in a class). In this context, network analysis is typically used to compare patterns of intra- versus intercategory communication. For example, in landmark works on social capital in communities (Bourdieu, 1985; Coleman, 1990; Putnam, 2000), group boundaries such as social class played a key role in creating denser subsidiary networks within classes. These dense networks facilitated both the spread and enforcement of norms through the diffusion of reputations, iterated relationships, and threat of sanctions. The analog in the small group arena would be groups with clearly defined boundaries and membership. Members are viewed as belonging to one particular group (just as people are thought of as belonging to a particular social class or category), not as belonging to multiple overlapping groups.

\section{CORE PRINCIPLES OF THE NETWORK PERSPECTIVE}

The network approach spans a broad range of disciplines, including sociology, social psychology, mathematics, political science, communication, anthropology, economics, and epidemiology. There is no single formal statement of the network perspective. Yet, there are certain core ideas that all or most network scholars would likely endorse. Barry Wellman (1988) has identified five fundamental principles that provide some "underlying intellectual unity" to the network approach.

First, people's behavior is best predicted by examining not their drives, attitudes, or demographic characteristics, but rather the web of relationships in which they are embedded. That web of relationships presents opportunities and imposes constraints on people's 
behavior. If two people behave in a similar fashion, it is likely because they are situated in comparable locations in their social networks, rather than because they both belong to the same category (e.g., both are White women).

Second, the focus of analysis should be the relationships between units, rather than the units themselves or their intrinsic characteristics. Nothing can be properly understood in isolation or in a segmented fashion.

Third, analytic methods must not hinge on the conventional assumption of independence. A population or sample is defined relationally rather than categorically. Therefore, interdependence among units is assumed.

Fourth, understanding a social system requires more than merely aggregating the dyadic ties. The flow of information and resources between two people depends not simply on their relationship to each other but on their relationships to everybody else. For example, it matters whether two people who communicate with one another are embedded within a cluster of individuals who also talk to one another, versus embedded within two separate clusters that otherwise do not communicate at all (Burt, 1992).

Fifth, groups sometimes have fuzzy rather than firm boundaries. The building blocks of organizations are not discrete groups but rather overlapping networks. Individuals generally have cross-cutting relationships to a multitude of groups. Applying these five principles to small groups, a network study focuses on relationships between components in the group system-individual-toindividual ties within a group, individual-to-group ties, or groupto-environment ties - rather than on features of these components.

\section{THEORETICAL ROOTS OF THE NETWORK PERSPECTIVE}

How do network scholars explain why people create, maintain, dissolve, and possibly reconstitute network ties, and who is likely to form ties with whom? There are multiple schools of thought or "families of theories" (Monge \& Contractor, 2003) within the net- 
work perspective that approach this question from different vantage points. These include theories of self-interest, theories of social exchange or dependency, theories of mutual or collective interest, cognitive theories, and theories of homophily. We briefly describe each school, highlighting its intellectual forebears and its central theoretical mechanisms.

There is a large school of network researchers who come from a rational self-interest paradigm. These scholars assume that people form dyadic and group ties in order to maximize their personal preferences and desires. The rational self-interest school within network research can be traced back to the work of sociologist James Coleman (1988). Coleman showed how, from two-actor interactions, with each actor operating out of self-interest, emerges the basis for a social system (such as a small group). While each actor is trying to maximize his or her individual interests, each is at the same time constrained because he or she is embedded in an interdependent relationship with the other. That relationship imposes limits on both actors' behavior and regulates the extent of self-seeking. These limits are counterbalanced by the increased access to resources each actor gets via the other.

Individuals consider the creation of ties as an investment in the accumulation of social resources or "social capital." Social capital is the "sum of the resources, actual or virtual, that accrue to an individual or group by virtue of possessing a durable network of more or less institutionalized relationships of mutual acquaintance and recognition" (Bourdieu \& Wacquant, 1992, p. 119). From a selfinterest perspective, individuals expect to deploy this social capital (Coleman, 1988, 1990; Lin, 2001) and reap returns on their investment in the form of opportunities from which they can profit. For instance, Burt (1992, 1997, 1998, 2001) argues that "structural holes" in a network provide an opportunity for individuals to invest their social capital. Individuals fill a structural hole when they make efforts to connect two or more others who are not directly connected. The return on their investments accrues from their ability to "broker" the flow of knowledge and information between those who are not directly connected. 
A second school of network researchers draws upon theories of social exchange and dependency. George Homans (1950) was a forebear of the social exchange school. Homans asserted that people establish ties to others with whom they can exchange valued resources. Whether a relationship will be sustained over time will depend on the payoffs to each of the two parties. With exchange theory, Homans sought to link the micro to the macro levels of analysis and show how the social structure arises from these one-onone interactions. Richard Emerson (1972a, 1972b) enlarged the focus of exchange theory to look beyond the dyad at the network of relationships in which the dyad is embedded. Emerson examined exchanges and power dependences at both the interindividual and intergroup levels. He argued that when individuals or groups exchange valued resources, this is made possible due to a largescale network of relationships. Unlike theories of self-interest, individuals' motivation to create ties with others is not based on maximizing their personal investments. Instead, individuals' motivation to create ties is based on their ability to minimize their dependence on others from whom they need resources and maximize the dependence of others who need resources they can offer. A social exchange calculus is often an optimal strategy to manage these dependencies. These dependencies, social exchange theorists argue, constitute the glue that binds a group together. Several scholars have developed this perspective on dyads and groups into what is now commonly referred to as network exchange theory (Bienenstock \& Bonacich, 1992, 1997; Cook, 1977, 1982; Cook \& Whitmeyer, 1992; Willer \& Skvoretz, 1997).

A third influential network perspective draws on theories of mutual interest and collective action. Its main premise is that "mutual interests and the possibility of benefits from coordinated action" (Marwell \& Oliver, 1993, p. 2) often outweigh individual self-interests. Public goods theory, first articulated by Samuelson (1954), is one of the best developed theories of collective action. It was developed to explain the economics of collective versus private ownership of material infrastructure such as parks, bridges, and tunnels. More recently, it has been extended to explain the collective production and ownership of intellectual property (e.g., ideas, 
documents, decisions), such as that developed by small groups (Fulk, Flanagin, Kalman, Monge, \& Ryan, 1996; Lessig, 2001; Monge et al., 1998).

Public goods theory seeks to explain the conditions under which group members contribute to the creation and maintenance of public goods so that everyone in the collective will be able to benefit from them. An important focus has been the role of communication networks in creating and maintaining these public goods. The calculus of mutual interest or collective action suggests that individuals will create ties and coalesce into groups not because it maximizes the self-interest of any individual within the group or even the exchange value between individuals in the group. Instead, the motivation to forge ties and form a group is to maximize their collective ability to leverage resources and mobilize for collective action in their environment. One of the defining features of a public good is the impossibility of exclusion (Hardin, 1982; Olson, 1965; Samuelson, 1954). That is, every member of the group has a right to benefit from the public good, irrespective of their contribution to its creation or maintenance. We know this phenomenon in the literature on group research as the "free rider" problem. Studying groups from a network perspective gives us the potential to better understand and mitigate this problem.

A fourth network perspective on group research draws on a family of cognitive theories. Two of these theories are particularly relevant for the study of small groups: the theory of transactive memory systems and the theory of cognitive consistency. Whereas both theories focus on group members' cognitions, they differ in their explanation for why group members create and maintain their network ties. The theory of transactive memory explains how group members, each with their own set of skills and expertise, develop communication networks that help them identify and leverage the skills and expertise of others in the group (Hollingshead, 1998; Moreland, 1999; Wegner, 1987, 1995). These network ties facilitate flows of knowledge within the group, thereby reducing the need for each group member to possess skills or expertise available elsewhere in the group. Hollingshead, Fulk, and Monge (2002) offer an intriguing argument for combining the explanatory mecha- 
nisms offered by transactive memory theory and public goods theory (described above) to study the use of intranets or other knowledge repositories by groups.

Whereas the theory of transactive memory focuses on what members think other group members know, cognitive consistency theory focuses on whom members think other group members like. Heider's (1958) balance theory posited that if two individuals were friends, they should have similar evaluations of an object. This model was extended and mathematically formulated by Harary, Norman, and Cartwright (1965). Holland and Leinhardt (1975) argued that the object could be a third person in a communication network. If the two individuals did not consistently evaluate the third person, they would experience a state of discomfort and would strive to reduce this cognitive inconsistency by altering their evaluations of either the third person or their own friendship. In common parlance, this argument is captured by the aphorism "We like to be friends with friends of our friends" and the occurrence of tension when our friends are not friends with one another. In small groups, these affect ties ("who likes whom") are an important explanation of the creation of communication ties within a group and the development of coalitions within groups. Researchers have examined the effects of cognitive consistency on individuals' attitudes. For instance, Krackhardt and Kilduff (1990) reported that members whose friends were friends with one another (they labeled this "schema consistent") tended to be more satisfied than those whose friends did not get along with one another.

Fifth, a network perspective can help explain group communication on the basis of homophily. That is, members are more likely to create communication ties with other group members who they deem to be similar. In colloquial terms, "birds of a feather flock together." Brass (1995a) observes that "similarity is thought to ease communication, increase predictability of behavior, and foster trust and reciprocity" (p. 51). Indeed, the similarity-attraction hypothesis (Byrne, 1971) is exemplified in the work of Sherif (1958), who suggested that individuals were more likely to select similar others because by doing so they reduce the potential areas of conflict in the relationship. 
A key issue for theories of homophily is determining the criteria used to evaluate similarity. Homophily has been studied on the basis of similarity in age, gender, education, prestige, social class, tenure, and occupation (Carley, 1991; Coleman, 1957; Ibarra, 1992, 1995; Laumann, 1966; Marsden, 1988; McPherson \& Smith-Lovin, 1987). The theory of self-categorization (Turner \& Oakes, 1986, 1989) offers important insights into which criterion (or criteria) is likely to be salient in judging similarity with other group members. Turner and Oakes $(1986,1989)$ argue that group members define their social identity through a process of self-categorization, during which they classify themselves and others using categories such as age, race, and gender. The manner in which individuals categorize themselves influences the extent to which they associate with others who are seen as falling into the same category.

In today's increasingly virtual environments, group members often do not have access to visual cues, and, hence, categories such as age and gender might become less salient than more abstract categories such as professional identity. As a result, groups in which members perceive others as being similar are likely to have less conflict and more satisfaction. However, depending on the criteria used for judging similarity, these groups might also attenuate their exposure to diverse perspectives and, hence, affect their creativity (Brass, 1995b). A communication network perspective has the ability to explain (a) what criteria are used by group members to identify similar others and (b) how these criteria are invoked to create communication ties with similar others.

\section{REVIEW OF THE EMPIRICAL RESEARCH}

In this section, we provide a sense of the historical trajectory of research on small group networks and a chronological summary of the highlights in the research. (For a more comprehensive and detailed account of the research, see Katz, Lazer, Arrow, \& Contractor, in press). There are two clearly definable surges in research on small group networks: the 1950s and 1960s (the "early era"), and the 1990s and 2000s (the "current era"). The early era was 
devoted to experimental research, primarily emanating from the Group Networks Laboratory at MIT. The current era has consisted of both laboratory and field research.

The early era. In the 1950s and 1960s, Bavelas and Leavitt and their colleagues at MIT conducted a series of experiments on small group networks. They manipulated the pattern of communication among the members of small groups by controlling who could send messages to whom, and measured the impact of various patterns on group functioning and performance (Bavelas, 1950; Bavelas \& Barrett, 1951; Leavitt, 1951). Figure 1 provides a sample of the types of five-person configurations they studied.

The researchers found that centralization - the extent to which one person served as a hub of communication-had a significant impact on individual and group functioning. The complexity of the task proved to be a critical moderating variable: Centralization was beneficial when the task was simple and detrimental for complex tasks. A decentralized structure was also best when information was distributed unevenly among group members, or when the information was ambiguous (Leavitt, 1951; Shaw, 1954, 1964, 1971).

Bavelas and Leavitt focused on the question, What is the optimal network for group performance? Guetzkow and Simon (1955) replicated these experiments but extended the scope of the research by examining the actual pattern of signal sending (as opposed to treating the pattern of signal sending as a given, entirely prescribed by the experimenters). That is, for any given communication network that Bavelas $(1950,1951)$ imposed on the group by limiting communication channels, there are a number of potential patterns that the group could actually adopt. Guetzkow and Simon (1955) showed that group members made choices in their communication patterns, and these choices greatly affected the efficiency of the designs that Bavelas et al. tested.

It is interesting to note that research on small group networks was a fallow area in the 1970s and 1980s. What accounts for this lull? We cannot be sure, but we suspect two phenomena may have been operating. First, the research paradigm adopted by the Group 
B

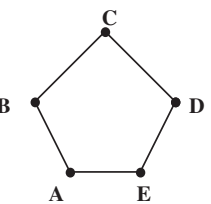

Circle

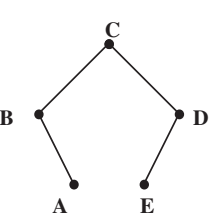

Chain

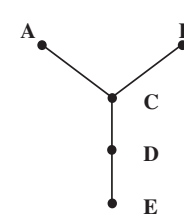

$\mathbf{Y}$

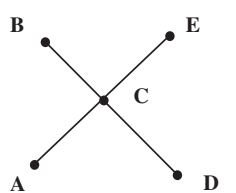

Wheel

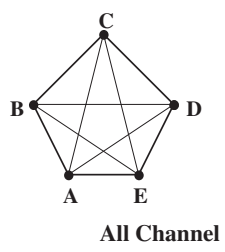

Figure 1: Sample of Five-Person Network Patterns

Networks Laboratory, where channels of communication were imposed by the experimenters, was limited in the questions it could address. By the mid-1970s, many small group and communication researchers' interests had shifted from the laboratory to the field (Downs, Clampitt, \& Pfeffer, 1988). Second, research on networks migrated to the field of sociology. Small groups and networks became independent areas of study.

The current era. Research on small group networks began to experience a resurgence in the 1990s. Again, we can only speculate as to the reasons for this development. We suspect this is partly because network analysis of organizational and interorganizationallevel phenomena has greatly grown and matured over the last 20 years. In particular, the social network construct of social capital has received tremendous attention since Putnam (1993). The popularity of network notions is now filtering down to the group level of analysis. Network researchers, traditionally focused on individualand organizational-level networks, are expanding their focus to include group-level networks. Small group researchers are curious to learn whether network methods might add to their understanding 
of and traction on small group phenomena. Thus, the two bifurcated streams of research are coming together again.

In this section, we provide an overview of the highlights of the recent research on small group networks. We organize the research into two general categories: a group's internal and external network ties. (It is interesting that Flap, Bulder, \& Volker, 1998, have called for a similar conceptual separation between an organization's internal and external ties.)

\section{INTERNAL NETWORK TIES}

Several researchers have returned to the question that Bavelas et al. raised-What is the optimal network for group performance? - but broadened the scope of the investigation by moving from the laboratory to the field.

Sparrowe, Liden, Wayne, and Kraimer (2001) conducted a field study of 38 work groups in five organizations, where the groups were performing relatively complex tasks. Sparrowe et al. replicated the early findings; with a complex task, groups with decentralized communication patterns performed better than groups with centralized communication patterns. In a study of 182 work groups performing complex tasks in a global organization, Cummings and Cross (2003) also found that groups with decentralized communication patterns outperformed more centralized groups. LipmanBlumen and Leavitt (2001) applied these findings regarding centralization to their theory of high-performing "hot groups," whose success is due in part to their fluid, decentralized communication structures.

Other researchers have focused on the question, What conditions influence the emergence of a centralized pattern of ties? Argote, Turner, and Fichman (1989) assigned groups to either a high-stress or low-stress condition. They found that stressed groups developed more centralized communication networks, consistent with earlier research into threat-rigidity effects (Staw, Sandelands, \& Dutton, 1981). Brown and Miller (2000) conducted an experiment in which half of the groups were given a high-complexity version of the task, and half were given a low-complexity 
version. Brown \& Miller found that more centralized communication patterns developed in the groups that worked on the low-complexity than the high-complexity task.

Other researchers have focused on the number rather than the pattern of communication links among group members. Baldwin, Bedell, and Johnson (1997) and Reagans and Zuckerman (2001) established in field studies that groups with more ties outperformed groups with fewer ties. On a more theoretical level, Markovsky and colleagues have examined the conditions under which internal ties between group members could impair group performance. Markovsky et al. have considered subgroup formation as a source of friction that could degrade the overall solidarity of a larger unit. When people become involved in exclusive friendship cliques within a larger group, the unity of structure is disrupted (Markovsky \& Chaffee, 1995; Markovsky \& Lawler, 1994), and internal divisions between subgroups can weaken the group structure.

In an interesting development, a number of researchers are reconceptualizing groups as a set of dynamic relations between people, tools, and tasks that form a complex system. Tschan and von Cranach (1996), for example, consider how tasks are connected to one another within the larger frameworks of group projects. Krackhardt and Carley (2003), in their PCANS (precedence, commitment, assignment, network, and skill) model of organizational structure, develop a formalization of how people, tasks, and resources can be represented. Arrow, McGrath, and Berdahl (2000) draw on network theory and complexity science to develop a model of groups as composed of a dynamic "coordination network" connecting and organizing members, tasks, and tools. The full group network can be decomposed into networks that connect elements of a single type (people, tasks, or tools) and those that connect different types of nodes, providing network definitions of concepts such as the division of labor (the set of links that connect people to tasks) and roles (the set of links that connect people to tools and resources), and generating new constructs such as the "job network," which specifies which tools and procedures are to be used to complete which tasks. The differential importance of the component networks within groups provides the basis for distinguishing 
between types of groups, such as "task forces" (in which the task and labor networks are primary), "crews" (in which the tool and job networks are primary), and "teams" (in which the member and role networks are primary).

This recent era of research on the internal networks of small groups opens new vistas for fruitful investigation. The early experimental research that divided tasks into simple versus complex, although an important first step, undervalued variables that might interact with network structure to produce outcomes. The currently emerging framework-reconceptualizing groups as consisting of multiple component networks-will help us understand how the value of a particular network structure is contingent on the distribution of knowledge and other resources as well as task structure.

\section{EXTERNAL NETWORK TIES}

To understand how a group functions, it is essential to examine the context in which that group is embedded (Stohl \& Putnam, 2003) and how the group manages its relationship with key players in its environment (Ancona \& Caldwell, 1992). This research focuses on ties to particular strategic others, as well as the overall structure of those ties (as measured in quantity and pattern), where the ties may be to other groups or to the environment. Group members who draw on external ties to access resources for the group are called boundary spanners.

Research on interlocking boards of directors supports the notion that external group ties can play an important role in group success (e.g., Mizruchi, 1996) by providing useful knowledge from other boards (G. F. Davis, 1991; Haunschild, 1993). Some researchers, however, have reported mixed findings regarding the importance of boundary-crossing ties. Baldwin et al. (1997) found no relationship between a team's external ties and its performance. Sparrowe et al. (2001) found a strong negative relationship between a team's external ties and performance. Baldwin et al. (1997) suggest that their null findings simply reflect the fact that groups in their study had little need for external communication; due to the nature of the task, 
the configuration of internal ties was more important than external ties. In other words, a group's need for external resources, as defined by the nature of the task, moderates the impact of external ties.

We believe work by Hansen (1999) and Haas (2002) may help resolve the discrepancy between Sparrowe et al.'s (2001) results (external ties can hurt a team's performance) and the other research suggesting external ties can be a valuable source of information and resources. Hansen (1999) found an interaction between tie strength and the complexity of information being transmitted. Weak ties worked best for bringing simple information from the external environment into the team. Complex information required the "bandwidth" of strong ties. The inconsistency between Ancona \& Caldwell's (1992) and Sparrowe et al.'s (2001) findings might be the result of not differentiating between strong and weak ties. Furthermore, Haas (2002) found that having many external ties may be either beneficial or harmful for a team, depending on a number of factors, including autonomy and task overload. For teams with little autonomy or with overloaded members, communication initiated by the external environment negatively affected group performance.

External ties can influence group performance through other mechanisms, in addition to information flow. Nelson (1989) found that the frequency of strong cross-group ties was associated with lower levels of conflict within organizations. Lazer and Katz (2003a) report that when group members shared many overlapping external ties, they were less likely to free ride on one another's efforts. In other words, structural embeddedness (Granovetter, 1985; Uzzi, 1996) regulated the effort level of group members. These and other findings suggest that the impact of external ties may depend on a whole set of structural and institutional contingencies that are just beginning to be explored. This finding highlights the broader trade-off teams face in having redundant external ties, which would limit opportunistic behavior, as compared with having nonredundant external ties, which would offer greater access to information and resources (Burt, 1992). 


\section{BENEFITS}

In this section, we identify three important benefits that can result from applying a network perspective to small groups. First, principles of the network perspective can help small group researchers gain traction in investigating phenomena that have proved difficult to pin down. Group context is a good example. From a network perspective, group context is viewed as the larger social structure of connections between people, resources, and other collectives in which a group is embedded and to which it is connected. In line with the key theoretical principles, social network analysis offers an array of methodological tools for investigating connections between a group and its external context.

Indeed, in recent years, a number of small group scholars have called for more theory and research that attends to the group's external environment (e.g., Stohl \& Putnam, 2003) and how a group manages its relationship with strategic outsiders (Ancona \& Caldwell, 1992). Network theory offers a structured way of conceptualizing and measuring external ties and their impact. Ties may spring from individual group members or from the group as a whole. Ties may connect groups or members to external individuals, groups, or resources.

Second, the network perspective can help researchers integrate the internal workings of the group and the group's external environment. Studies have generally focused on either the relationships between group members (e.g., cohesiveness, coordination, etc.) or on the group's relationship with outsiders, but network methods can help researchers to examine how the two interact. For example, Lazer and Katz (2003a) found that group members' shared ties to friends outside the group influenced the extent of social loafing by group members. (Of course, this benefit is pertinent only when analyzing groups with clearly delineated boundaries.)

Third, network analysis offers techniques for identifying and exploring important features of small group interaction. Although one such feature - centralization - has already received substantial attention, network techniques can help researchers assess other, 
potentially important, features of small group interaction. For example, how do isolates (individuals without any ties) affect group functioning? (e.g., Thomas-Hunt, Ogden, \& Neale, 2003). Do the capabilities of particular nodes (e.g., the central node) matter? As group membership changes over time, how do the addition and deletion of nodes-and the requisite reconfiguration of relationships—affect group dynamics?

\section{CHALLENGES}

In this section, we describe the primary challenges now facing researchers who apply network concepts to the study of small group networks. The first challenge involves being clear about the position of the network in the causal chain. The second challenge involves extrapolating from one level of analysis to another.

The bulk of social network analysis to date has been static in nature, typically consisting of a one-time snapshot of the network ties. The lack of longitudinal analysis then leads to the challenge of causal inference: determining which is causally antecedent, the network or the hypothesized effects of the network (Lazer, 2001). A challenge in combining network and group approaches, then, is that the success or failure of a group may affect the structure of the group network (both internal and external). Would it be surprising to find that successful groups are more cohesive, have more informal ties, fewer cliques, and structural holes, even if there were no effects of network ties on effectiveness? It is therefore necessary to collect network data that are causally antecedent to the outcome that is hypothesized to have been determined by them.

Because network data are typically collected after groups have produced outputs (and received feedback), it is impossible to say whether the network patterns are the result of connectedness leading to success or success leading to connectedness. To fully understand the causal relationships between networks and group performance, four analytically and temporally distinct stages must be considered: (a) the network that exists before the group, (b) the net- 
work in the group formation process, (c) the network while the group does its work, and (d) the network once the group has concluded functioning (Lazer \& Katz, 2003b).

Notably, however, the field has begun to wrestle with this issue, with the application of simulation analysis to study the dynamics of networks (Carley, 2003), and the development of statistical methods, such as Monte Carlo maximum likelihood procedures, to examine longitudinal data (Huisman \& Snijders, 2003; for a review, see Wasserman and Robins, 2003). Although these new methodologies have yet to make a widespread impact, they have the potential to be transformational.

In applying the network perspective to the domain of small groups, it is important to keep in mind the question, When is it appropriate to map network concepts onto the small group domain, and when is it not appropriate? This conceptual mapping needs to be done with some caution, because, for example, a finding about what makes an organization effective in an interorganizational network might not be usefully extrapolated to what makes an individual effective in a group. The key issue is whether a process or construct works at multiple levels (Brass, 2000). For example, if the process is information diffusion, a network position that is advantageous to the individual (e.g., centrality) might reasonably be argued to map to other levels of analysis, such as the group (in an intraorganizational network of groups) or the organization (in an interorganizational network of organizations). However, if the process or construct is distinctive to a particular level of analysis, it would be unwise to map to other levels. For example, an intrapsychic construct that "lives" at the individual level, such as "need for cognition," might not make sense at the organizational level.

\section{SUMMARY}

Network research into small group phenomena experienced a promising beginning in the 1950s and 1960s. The topic was 
neglected in the 1970s and 1980s but has recently undergone revitalization, and much promising work has been done in the last 15 years. The network perspective has a great deal to offer small group researchers. By adopting network methods and concepts, small group scholars can increase their traction on group-level phenomena as well as model phenomena that cross levels of analysis (such as individual-to-group ties and group-to-organization ties). One area especially deserving of future development is the longitudinal analysis of groups and networks.

\section{REFERENCES}

Ancona, D. G., \& Caldwell, D. F. (1992). Bridging the boundary-external activity and performance in organizational teams. Administrative Science Quarterly, 37, 634-665.

Argote, L., Turner, M. E., \& Fichman, M. (1989). To centralize or not to centralize: The effects of uncertainty and threat on group structure and performance. Organizational Behavior and Human Decision Processes, 43, 58-74.

Arrow, H., McGrath, J. E., \& Berdahl, J. L. (2000). Small groups as complex systems: Formation, coordination, development, and adaptation. Newbury Park, CA: Sage.

Baldwin, T. T., Bedell, M. D., \& Johnson, J. L. (1997). The social fabric of a team-based MBA program: Network effects on student satisfaction and performance. Academy of Management Journal, 40, 1369-1397.

Batagelj, V. A., \& Mrvar, A. (2003). Pajek: Analysis and visualization of large networks. In M. Jünger \& P. Mutzel (Eds.), Graph drawing software (pp. 77-103). Berlin: Springer.

Bavelas, A. (1950). Communication patterns in task-oriented groups. Journal of the Acoustical Society of America, 22, 723-730.

Bavelas, A., \& Barrett, M. (1951). An experimental approach to organisational communication. Personnel, 27, 386-397.

Bienenstock, E. J., \& Bonacich, P. (1992). The core as solution to exclusionary networks. Social Networks, 14, 231-244.

Bienenstock, E. J., \& Bonacich, P. (1997). Network exchange as a cooperative game. Rationality and Society, 9, 37-65.

Borgatti, S. (2003). NetDraw: Network visualization software. Available online at http:// www.analytictech.com/netdraw.htm

Bourdieu, P. (1985). The forms of capital. In J. G. Richardson (Ed.), Handbook of theory and research for the sociology of education (pp. 241-258). New York: Greenwood.

Bourdieu, P., \& Wacquant, L. J. D. (1992). An invitation to reflexive sociology. Chicago: University of Chicago Press.

Brass, D. J. (1995a). A social network perspective on human resources management. Research in Personnel and Human Resources Management, 13, 39-79.

Brass, D. J. (1995b). Creativity: It's all in your social network. In C. M. Ford \& D. A. Gioia (Eds.), Creative action in organizations (pp. 94-99). London: Sage. 
Brass, D. J. (2000). Networks and frog ponds: Trends in multilevel research. In K. J. Klein \& S. W. J. Kozlowski (Eds.), Multilevel theory, research, and methods in organizations (pp. 557-571). San Francisco: Jossey-Bass.

Brown, T. M., \& Miller, C. E. (2000). Communication networks in task-performing groups: Effects of task complexity, time pressure, and interpersonal dominance. Small Group Research, 31, 131-157.

Burt, R. S. (1992). Structural holes: The social structure of competition. Cambridge, MA: Harvard University Press.

Burt, R. S. (1997). The contingent value of social capital. Administrative Science Quarterly, 42, 339-365

Burt, R. S. (1998). The gender of social capital. Rationality and Society, 10, 5-46.

Burt, R. S. (2001). Structural holes versus network closure as social capital. In N. Lin, K. Cook, \& R. S. Burt (Eds.), Social capital: Theory and research (pp. 31-56). New York: Aldine de Gruyter.

Byrne, D. (1971). The attraction paradigm. New York: Academic Press.

Carley, K. M. (1991). A theory of group stability. American Sociological Review, 56, 331354.

Carley, K. M. (2003). Dynamic network analysis. In R. Breiger, K. M. Carley, \& P. Pattison (Eds.), Dynamic social network modeling and analysis: Workshop summary and papers. (pp. 134-145). Washington, DC: The National Academies Press.

Coleman, J. S. (1957). Community conflict. New York: Free Press.

Coleman, J. S. (1988). Social capital in the creation of human-capital. American Journal of Sociology, 94, S95-S120.

Coleman, J. S. (1990). Foundations of social theory. Cambridge: Belknap Press.

Cook, K. S. (1977). Exchange and power in networks of interorganizational relations. Sociological Quarterly, 18, 62-82.

Cook, K. S. (1982). Network structures from an exchange perspective. In P. V. Marsden \& N. Lin (Eds.), Social structure and network analysis (pp. 177-218). Beverly Hills, CA: Sage.

Cook, K. S., \& Whitmeyer, J. M. (1992). Two approaches to social structure: Exchange theory and network analysis. Annual Review of Sociology, 18, 109-127.

Cummings, J. N. (2004). NetVis Module: Dynamic visualization of social networks. Available online at http://www.netvis.org/

Cummings, J. N., \& Cross, R. (2003). Structural properties of work groups and their consequences for performance. Social Networks, 25, 197-281.

Davis, A., Gardner, B. B., \& Gardner, M. R. (1941). Deep South: A social anthropological study of caste and class. Chicago: University of Chicago Press.

Davis, G. F. (1991). Agents without principles: The spread of the poison pill through the intercorporate network. Administrative Science Quarterly, 36, 583-613.

Downs, C. W., Clampitt, P. G., \& Pfeffer, A. (1988). Communication and organizational outcomes. In G. Goldhaber \& G. Barnett (Eds.), Handbook of organizational communication (pp. 171-211). Norwood, NJ: Ablex.

Emerson, R. M. (1972a). Exchange theory: Part I. A psychological basis for social exchange. In J. Berger, M. Zelditch, \& B. Anderson (Eds.), Sociological theories in progress (pp. 38-57). Boston: Houghton Mifflin.

Emerson, R. M. (1972b). Exchange theory: Part II. Exchange relations and networks. In J. Berger, M. Zelditch, \& B. Anderson (Eds.), Sociological theories in progress (pp. 58-87). Boston: Houghton Mifflin. 
Flap, H., Bulder, B., \& Volker, B. (1998). Intra-organizational networks and performance: A review. Computational \& Mathematical Organizational Theory, 4, 109-147.

Freeman, L. C. (1992). The sociological concept of group: An empirical test of 2 models. American Journal of Sociology, 98, 152-166.

Fulk, J., Flanagin, A. J., Kalman, M. E., Monge, P. R., \& Ryan, T. (1996). Connective and communal public goods in interactive communication systems. Communication Theory, 6, 60-87.

Granovetter, M. (1973). The strength of weak ties. American Journal of Sociology, 81, 12871303.

Granovetter, M. (1982). The strength of weak ties: A network theory revisited. In R. Collins (Ed.), Sociological theory 1983 (pp. 105-130). San Francisco: Jossey-Bass.

Granovetter, M. S. (1985). Economic action and social structure: The problem of embeddedness. American Journal of Sociology, 91, 481-510.

Guetzkow, H., \& Simon, H. A. (1955). The impact of certain communication nets upon organization and performance in task-oriented groups. Management Science, 1, 233-250.

Haas, M. R. (2002). Acting on what others know: Distributed knowledge and team performance. Unpublished doctoral dissertation, Harvard University, Cambridge, MA.

Hansen, M. T. (1999). The search-transfer problem: The role of weak ties in sharing knowledge across organization subunits. Administrative Science Quarterly, 44, 82-111.

Harary, F., Norman, R. Z., \& Cartwright, D. (1965). Structural models: An introduction to the theory of directed graphs. New York: John Wiley.

Hardin, R. (1982). Collective action. Baltimore: John Hopkins University Press.

Haunschild, P. R. (1993). Interorganizational imitation: The impact of interlocks on corporate acquisition activity. Administrative Science Quarterly, 38, 564-592.

Heider, F. (1958). The psychology of interpersonal relations. New York: John Wiley.

Holland, P. W., \& Leinhardt, S. (1975). Dynamic-model for social networks. Journal of Mathematical Sociology, 5, 5-20.

Hollingshead, A. B. (1998). Retrieval processes in transactive memory systems. Journal of Personality and Social Psychology, 74, 659-671.

Hollingshead, A. B., Fulk, J., \& Monge, P. (2002). Fostering intranet knowledge-sharing: An integration of transactive memory and public goods approaches. In P. Hinds \& S. Kiesler (Eds.), Distributed work. Cambridge, MA: MIT Press.

Homans, G. (1950). The human group. New York: Harcourt, Brace.

Huisman, M., \& Snijders, T. A. B. (2003). Statistical analysis of longitudinal network data with changing composition. Sociological Methods \& Research, 32, 253-287.

Ibarra, H. (1992). Homophily and differential returns: Sex differences in network structure and access in an advertising firm. Administrative Science Quarterly, 37, 422-447.

Ibarra, H. (1995). Race, opportunity, and diversity of social circles in managerial networks. Academy of Management Journal, 38, 673-703.

Katz, N., Lazer, D., Arrow, H., \& Contractor, N. S. (in press). Applying a network perspective to small groups: Theory and research. In M. S. Poole \& A. B. Hollingshead (Eds.), Theories of small groups: An interdisciplinary perspective. Newbury Park, CA: Sage.

Krackhardt, D., \& Carley, K. M. (2003). PCANS model of structure in organizations (CASOS Working Papers). Pittsburgh, PA: Carnegie-Mellon University.

Krackhardt, D., \& Kilduff, M. (1990). Friendship patterns and culture: The control of organizational diversity. American Anthropologist, 92, 142-154. 
Laumann, E. O. (1966). Prestige and association in an urban community. Indianapolis, IN: Bobbs-Merrill.

Lazer, D. M. (2001). The co-evolution of individual and network. Journal of Mathematical Sociology, 25, 69-108.

Lazer, D., \& Katz, N. (2003a, Spring). Regulating opportunism: The role of embeddedness in teams (Working paper). Cambridge, MA: John F. Kennedy School of Government, Harvard University.

Lazer, D., \& Katz, N. (2003b, Spring). Building effective organizational networks: The role of teams (Working paper). Cambridge, MA: Center for Public Leadership, John F. Kennedy School of Government, Harvard University.

Leavitt, H. J. (1951). Some effects of certain communication patterns on group performance. Journal of Abnormal and Social Psychology, 46, 38-50.

Lessig, L. (2001). The future of ideas: The fate of the commons in a connected world. New York: Random House.

Lin, N. (2001). Social capital: A theory of social structure and action. Cambridge, MA: Cambridge University Press.

Lipman-Blumen, J., \& Leavitt, H. J. (2001). Hot groups: Seeding them, feeding them, and using them to ignite your organization. Oxford, England: Oxford Press.

Markovsky, B., \& Chaffee, M. (1995). Social identification and solidarity: A reformulation. Advances in Group Processes, 12, 249-270.

Markovsky, B., \& Lawler, E. J. (1994). A new theory of group solidarity. In B. Markovsky, K. Heimer, \& J. O'Brien (Eds.), Advances in group processes (Vol. 11, pp. 113-137). Greenwich, CT: JAI.

Marsden, P. V. (1988). Homogeneity in confiding relations. Social Networks, 10, 57-76.

Marwell, G., \& Oliver, P. (1993). The critical mass in collective action: A micro-social theory. Cambridge, MA: Cambridge University Press.

McPherson, J. M., \& Smith-Lovin, L. (1987). Homophily in voluntary organizations: Status distance and the composition of face to face groups. American Sociological Review, 52, 370-379.

Mizruchi, M. S. (1996). What do interlocks do? An analysis, critique, and assessment of research on interlocking directorates. Annual Review of Sociology, 22, 271-298.

Monge, P. R., \& Contractor, N. (2003). Theories of communication networks. New York: Oxford University Press.

Monge, P. R., Fulk, J. K., Kalman, M., Flanagin, A. J., Parnassa, C., \& Rumsey, S. (1998). Production of collective action in alliance-based interorganizational communication and information systems. Organization Science, 9, 411-433.

Moreland, R. L. (1999). Transactive memory: Learning who knows what in work groups and organizations. In L. Thompson, D. Messick, \& J. Levine (Eds.), Sharing knowledge in organizations (pp. 3-31). Mahwah, NJ: Lawrence Erlbaum.

Nelson, R. E. (1989). The strength of strong ties: Social networks and intergroup conflict in organizations. Academy of Management Journal, 32, 377-401.

Newcomb, T. M. (1961). The acquaintance process. New York: Holt, Rinehart \& Winston.

Olson, M., Jr. (1965). The logic of collective action. Cambridge, MA: Harvard University Press.

Putnam, R. D. (1993). Making democracy work. Princeton, NJ: Princeton University Press.

Putnam, R. D. (2000). Bowling alone: The collapse and revival of American community. New York: Simon \& Schuster. 
Reagans, R., \& Zuckerman, E. W. (2001). Networks, diversity, and productivity: The social capital of corporate R\&D teams. Organization Science, 12, 502-517.

Samuelson, P. (1954). The pure theory of public expenditure. Review of Economics and Statistics, 36, 387-389.

Shaw, M. (1971). The psychology of small group behavior. New York: McGraw-Hill.

Shaw, M. (1964). Communication networks. In L. Berkowitz (Ed.), Advances in experimental psychology (pp. 111-147). New York: Academic Press.

Shaw, M. E. (1954). Some effects of unequal distribution of information upon group performance in various communication nets. Journal of Abnormal and Social Psychology, 49, 547-553.

Sherif, M. (1958). Superordinate goals in the reduction of intergroup conflicts. American Journal of Sociology, 63, 349-356.

Sparrowe, R. T., Liden, R. C., Wayne, S. J., \& Kraimer, M. L. (2001). Social networks and the performance of individuals and groups. Academy of Management Journal, 44, 316-325.

Staw, B. M., Sandelands, L. E., \& Dutton, J. E. (1981). Threat-rigidity effects in organizational behavior: A multi-level analysis. Administrative Science Quarterly, 21,378-397.

Stohl, C., \& Putnam, L. (2003). Communication in context: Implications for the study of bona fide groups. In L. R. Frey (Ed.), Group communication in context: Studies of natural groups (2nd ed., pp. 285-292). Hillsdale, NJ: Lawrence Erlbaum.

Thomas-Hunt, M. C., Ogden, T. Y., \& Neale, M. A. (2003). Who's really sharing? Effects of social and expert status on knowledge exchange within groups. Management Science, 49 , 464-477.

Tschan, F., \& von Cranach, M. (1996). Group task structure, processes, and outcome. In M. A. West (Ed.), Handbook of work group psychology (pp. 92-121). Chichester, England: John Wiley.

Turner, J. C., \& Oakes, P. J. (1986). The significance of the social identity concept for social psychology with reference to individualism, interactionism, and social influence. British Journal of Social Psychology, 25, 237-252.

Turner, J. C., \& Oakes, P. J. (1989). Self-categorization theory and social influence. In P. B. Paulus (Ed.), Psychology of group influence (pp. 233-275). Hillsdale, NJ: Lawrence Erlbaum.

Uzzi, B. (1996). The sources and consequences of embeddedness for the economic performance of organizations: The network effect. American Sociological Review, 61, 674698.

Wasserman, S., \& Faust, K. (1994). Social network analysis. Cambridge, MA: Cambridge University Press.

Wasserman, S., \& Robins, G. (2003). Introduction to random graphs, dependence graphs, and $p^{*}$. In Carrington, P. J., Scott, J., \& Wasserman, S. (Eds.), Models and methods in social network analysis. New York: Cambridge University Press.

Wegner, D. M. (1987). Transactive memory: A contemporary analysis of the group mind. In B. Mullen \& G. Goethals (Eds.), Theories of group behavior (pp. 185-208). New York: Springer-Verlag.

Wegner, D. M. (1995). A computer network model of human transactive memory. Social Cognition, 13, 319-339.

Wellman, B. (1988). Structural analysis: From method and metaphor to theory and substance. In B. Wellman \& S. Berkowitz (Eds.), Social structures: A network approach (pp. 19-61). Cambridge, England: Cambridge University Press. 


\section{SMALL GROUP RESEARCH / June 2004}

Willer, D., \& Skvoretz, J. (1997). Network connection and exchange ratios: Theory, predictions, and experimental tests. Advances in Group Processes, 14, 199-234.

Nancy Katz is associate professor of public policy at the John F. Kennedy School of Government at Harvard University. She earned her Ph.D. in organizational behavior from the joint program of Harvard Business School and the Harvard Psychology Department. Her research focuses on group dynamics, especially how to promote a healthy balance between cooperation and competition among members of a team.

David Lazer (Ph.D. in Political Science, 1996, University of Michigan) is associate professor of public policy at the Kennedy School of Government at Harvard University. Professor Lazer is cofounder and associate director of an NSF national center, the National Center for Digital Government Research and Practice (www.ncdg.org). He has published numerous papers on intraorganizational, interorganizational, and international networks.

Holly Arrow, a member of both the psychology department and the Institute for Cognitive and Decision Sciences at the University of Oregon, is coauthor, with Joseph McGrath and Jennifer Berdahl, of Small Groups as Complex Systems: Formation, Coordination, Development, and Adaptation, published by Sage. She studies the emergence and transformation of structure-including norms, influence hierarchies, and the cognitive networks of members-in small groups.

Noshir Contractor (Ph.D., 1988, Annenberg School for Communication, University of Southern California) is a professor of speech communication, psychology, and the Coordinated Science Laboratory at the University of Illinois at Urbana-Champaign. He is also a research affiliate of the Beckman Institute for Advanced Science and Technology and a Beckman Associate of the Center for Advanced Study at the University of Illinois at Urbana-Champaign. His research interests include applications of systems theories of complexity to communication, the role of emergent networks within and between organizations, and collaboration technologies in the workplace. For more information, see http://www.uiuc.edu/ph/www/nosh. 